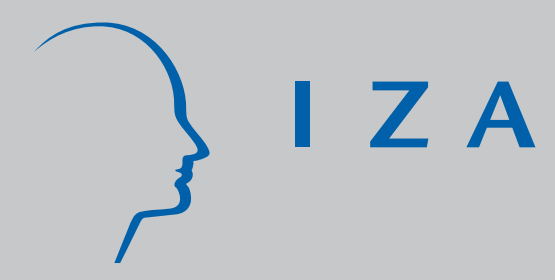

IZA DP No. 2557

Does a Food for Education Program Affect School Outcomes? The Bangladesh Case

Xin Meng

J im Ryan

J anuary 2007 


\title{
Does a Food for Education Program Affect School Outcomes? The Bangladesh Case
}

\author{
Xin Meng \\ Australian National University \\ and IZA \\ Jim Ryan \\ Australian National University \\ Discussion Paper No. 2557 \\ January 2007 \\ IZA \\ P.O. Box 7240 \\ 53072 Bonn \\ Germany \\ Phone: +49-228-3894-0 \\ Fax: +49-228-3894-180 \\ E-mail: iza@iza.org
}

\begin{abstract}
Any opinions expressed here are those of the author(s) and not those of the institute. Research disseminated by IZA may include views on policy, but the institute itself takes no institutional policy positions.

The Institute for the Study of Labor (IZA) in Bonn is a local and virtual international research center and a place of communication between science, politics and business. IZA is an independent nonprofit company supported by Deutsche Post World Net. The center is associated with the University of Bonn and offers a stimulating research environment through its research networks, research support, and visitors and doctoral programs. IZA engages in (i) original and internationally competitive research in all fields of labor economics, (ii) development of policy concepts, and (iii) dissemination of research results and concepts to the interested public.
\end{abstract}

IZA Discussion Papers often represent preliminary work and are circulated to encourage discussion. Citation of such a paper should account for its provisional character. A revised version may be available directly from the author. 


\section{ABSTRACT}

\section{Does a Food for Education Program Affect School Outcomes? The Bangladesh Case*}

The Food for Education (FFE) program was introduced to Bangladesh in 1993. This paper evaluates the effect of this program on school participation and duration of schooling using a household survey data collected in 2000 , after 7 years of operation of the program. Using propensity score matching combined with difference-in-differences methodologies we estimate the average effect of FFE eligibility on the schooling outcomes. We found that the program is successful in that the eligible children on average have 15 to 27 per cent higher school participation rates, relative to their counterfactuals who were not but would have been eligible for the program. Conditional on school participation, participants also stay at school 0.7 to 1.05 years longer than their counterfactuals.

JEL Classification: J38, 128

Keywords: education, program evaluation

Corresponding author:

Xin Meng

Division of Economics

Research School of Pacific and Asian Studies

Australian National University

Canberra 0200

Australia

E-mail: Xin.Meng@anu.edu.au

\footnotetext{
* The financial support of the International Food Policy Research Institute (IFPRI) is acknowledged with thanks. We are grateful to Akhter Ahmed at IFPRI for access to survey data and for facilitating the study in many other ways. Our thanks also go to Deborah Cobb-Clark, Bob Gregory, Tue Gorgens, Pushka Maitra, Linda Richardson, and other participants of the Australian Annual Labour Econometrics Workshop at Melbourne University.
} 


\section{Introduction}

Education is one of the most important forms of human capital investment. Yet, not all children have a chance to go to school. Some children from poor households are likely to be poor in the future because their parents are unable to invest in their education.

The government of Bangladesh introduced a Food for Education program (FFE) in July 1993. The main feature of the program is to provide a free monthly foodgrain ration contingent on the family being judged as poor and having at least one primary-school-age child attending school that month. The program is aimed at alleviation of both current and future poverty. The novelty of this program, relative to other poverty alleviation programs, is its commitment to long-term poverty alleviation via investment in children's education. Thus, to evaluate the effectiveness of this program, our main focus is on whether poor households who are eligible for the FFE program are more likely to send their children to school (school participation) and keep them there longer (duration of schooling) than their non-FFE counterfactuals.

There are two previous studies evaluating the FFE program on children's education (Ravallion and Woden, 2000; Ahmed and del Ninno 2002). Using an Instrumental Variable (IV) approach, these studies found that the amount of grain received through FFE program has a positive and significant impact on school participation rates.

The current paper differs from the previous studies by using propensity score matching combined with difference-in-differences methodologies to estimate the effect of FFE eligibility on school outcomes. We discuss the reasons for evaluating the effect of FFE "eligibility" rather than "receiving the grain-subsidy" in Section 3 after describing the institutional details of the program administration. In addition to the effect of FFE on the outcome of school participation, we also estimate the impact of the program on the children's completed duration of schooling, an outcome previous studies have not investigated. Our results reveal that the average effect of program eligible on school attendance is significantly larger than the effect of receiving the grain subsidies as presented in previous studies.

The paper is structured as follows. The next section introduces background details on the FFE program, the survey and the data used in the analyses. Section 3 describes the evaluation 
strategy. Sections 4 and 5 present the evaluation results. Conclusions are given in section 6 .

\section{Background, survey design and the data}

Bangladesh is a developing country and up to the mid 1980s rural education had been neglected. In the late 1980s and early 1990s, the government of Bangladesh realised the importance of education and identified the development of human capital as a primary strategy for reducing poverty.

In 1993 the FFE program was introduced. Its aim was to use targeted food transfers to encourage poor families to enrol children in primary school and to keep them there. The expectation was that the program would have three benefits: enhance human capital and hence reduce long-term poverty, provide nutritional gains and improve the targeting of government food subsidy programs. The program started in 1993 as a large-scale pilot program, and by 2000 the FFE covered some 17,811 primary schools (27 per cent of the total) and 2.1 million students (13 per cent). Of the 66,235 primary schools in Bangladesh, 62 per cent are government and 38 per cent non-government. The FFE covered government schools and four of the eight categories of non-government schools. The annual FFE program expenditure of around \$US 77 million represented 20 per cent of total expenditure on primary education in 1997/98, up from 4.7 per cent in 1993/94 (Ahmed and del Ninno 2002). The cost per beneficiary student is currently about \$US 0.10 per day. Food aid donors such as the U.S. also provided a significant portion of the grain for the program.

The FFE program delivers a free monthly foodgrain ration contingent on the family being judged as poor and having at least one primary-school-age child attending school that month. The local Primary Education Ward Committee and the School Management Committee jointly prepare the list of beneficiaries.

If one primary-school-age child from a designated poor family attends school the household is entitled to receive $15 \mathrm{~kg}$ of wheat or $12 \mathrm{~kg}$ of rice per month. To receive the maximum of $20 \mathrm{~kg}$ of wheat or $16 \mathrm{~kg}$ or rice, the household must send more than one child and all primary-school- 
age children to school. ${ }^{1}$ The enrolled children must attend 85 per cent of classes in a month to be able to receive a grain subsidy and records on this are kept by teachers and submitted monthly to the Thana (local government) offices. They and the School Management Committee then arrange with the Ministry of Food for the grain to be delivered to a nominated warehouse for collection by the beneficiary family using a ration card. The family can either consume the grain and/or sell it. Due to concerns about the loss in teaching time for food distribution, the Government in February 1999 relieved teachers of this responsibility and instead assigned the task to private dealers.

The FFE program uses a two-step targeting mechanism. First, 2 to 3 Unions (districts) that are economically backward and have a low literacy rate are selected from each of the 460 rural Thanas (regions). All government, registered non-government, community (low-cost), and satellite primary schools, and one Ebtedayee Madrasa (religion-based) primary school in these selected Unions are covered by the FFE program. Second, within each selected Union, households with primary-school-age children become eligible for FFE benefits if they meet at least one of the following four targeting criteria as assessed by the School Managment Committees:

1. A landless or near-landless household that owns less than half an acre of land;

2. The household head's principal occupation is day labourer;

3. The head of the household is female;

4. The household earns its living from low-income artisan occupations.

Although in FFE Union households which satisfy the above selection criteria are eligible for participation, four factors may prevent them from receiving the food subsidy: The first is that only primary-school students can participate. In other words, those who are not at primary school or who are enrolled in high school are not eligible. Second, only students who enrolled in FFE schools can receive the food subsidy. Some students from eligible households may enroll in non-FFE schools, and hence, cannot receive a food subsidy. Third, enrolled children must attend 85 percent of classes in a month to be able to receive a food subsidy. Those whose absent days exceed 15 percent (4 or more days in a month) would not receive the subsidy for

\footnotetext{
${ }^{1}$ According to the survey information, the sample households on average consume about $21 \mathrm{~kg}$ cereals per week. Hence, the subsidy received from the FFE program is almost equivalent to one quarter of the monthly supply of cereal products for an average household.
} 
the corresponding month. Fourth, only a maximum of 40 percent of students in each FFE school, including those who are not eligible, can receive the subsidy. Thus, if some schools have more than 40 percent of all the students who are eligible, some of these students do not receive a subsidy. In this situation, the decision as to who should receive the subsidy is made by the headmaster and teachers, and it may change over time. In other words, if a child from a FFE-eligible household enrolls in a FFE school but does not receive the food subsidy in one year, he/she could receive a subsidy in following years if others drop-out. Teachers endeavor to select the least poor households when they are faced with potentially eligible households beyond the 40 percent figure. It is not clear the extent to which they succeed. However, the survey data discussed below indicate that on average the household income of students who receive the subsidy is 12 percent lower than students who are eligible and enrolled in the FFE school but do not receive the subsidy, indicating, to a certain extent, that teachers do target the poorest when faced with an excess demand.

Previous evaluations of the FFE program have indicated that it has had a substantial effect on enrolments in primary school. In a sample survey of Bangladesh schools in 1996 Alam et al. (1999) found that the FFE schools had 53 per cent higher enrolments in Grade I than non-FFE schools and 30 per cent higher enrolments in Grade IV. In a different survey in 2001 Ahmed and del Ninno (2002) found that the effect of the amount of food-grain received through FFE program on children's primary school participation probability is about 8 percentage. Using the Bangladesh 1996 Household Expenditure Survey data for children aged 5 to 16, Ravallion and Wodon (2000) found that the amount of grain received through FFE program induces 15 per cent primary school participation rate.

In this paper we would like to evaluate the average effect of program eligibility on children's school outcomes. We conduct a program evaluation based on propensity score matching (PSM) combined with difference-in-differences methodology. Assuming that the Conditional Independence assumption is satisfied (we will discuss this issue in more detail in Section 3), the PSM method has the advantage of allowing for matching the eligible group with their proper counterfactuals, and hence, allowing us to estimate the average effect of eligibility on those who are eligible. 
The data used in this study are from a survey of schools, households, communities, and food grain dealers conducted by the IFPRI-FMRSP (Food Management and Research Support Project) in September-October, 2000. ${ }^{2}$ The sample includes 600 households from 60 villages in 30 Unions and 10 Thanas. The sampling follows four steps. First, 10 Thanas are randomly selected with probability proportional to their size (PPS), based on Thana level population data. Second, two FFE Unions and one non-FFE Unions per Thana were selected at random. Third, two villages from each Union were randomly selected with PPS, using village-level population data from the 1991 census. Fourth, 10 households that had at least one primary-school age child were randomly selected in each village from the census list of households.

Table 1 indicates the distribution of households and primary-school-aged children among FFE/non-FFE eligible households and FFE/non-FFE Unions in the sample. In total there are 400 households from FFE Unions and 200 from non-FFE Unions. Within FFE Unions, 209 households with 399 children of primary school age (aged 6 to 13$)^{3}$ are program eligible households and 191 households are non-eligible with 336 primary-school-aged children. In the non-FFE Union sample, the number of primary-school-aged children is 343.

As discussed earlier, not all children who are from eligible households actually participated in the FFE program. Table 2 presents the distribution of children aged 6 to 13 (primary-schoolaged children) according to their program eligibility. For children from eligible households in FFE Unions, around 14 per cent of them are not at school, and 6 to 8 per cent are attending nonFFE schools, depending on whether those who participated in the stipend program are included or not. ${ }^{4}$ In addition, there are 95 eligible children (24 per cent) attending FFE schools but not receiving the foodgrain subsidy. This may be due to either the 85 percent school attendance

\footnotetext{
${ }^{2}$ This survey was designed and conducted for the purpose of evaluating the FFE program. Detailed information on the survey was presented in Ahmed and del Ninno (2002). Ravallion and Wodon (2000) use the 1995-1996 Bangladesh nationwide Household Expenditure Survey.

${ }^{3}$ How to define "primary school age" is a difficult issue. According to Ahmed and del Ninno (2002), primary school starts at age 6 and finishes at age 10. However, many children start school late and some may repeat grades. As a result, the majority of 11 to 13 years olds in our sample are still at primary school. Including those who have never gone to a school, only 11 per cent of 11 year olds have finished primary school and these proportions for 12 and 13 years olds are 22 and 39 per cent, respectively. At age 14, this ratio increases to 60 per cent. Thus, following Ahmed and del Ninno (2002) we define our primary school sample as aged 6 to 13 years.

${ }^{4}$ The stipend program only operates in non-FFE Unions and consists of a small cash subsidy to poor households whose children attend school. The subsidy is only a fraction of that in the FFE program. In our later analysis we exclude observations that are receiving the stipend subsidy to insure that the estimated FFE program participation effect is not confounded by other factors.
} 
rule and/or the operation of the rule that a maximum of 40 percent of the students in each FFE school can participate in the program at any one point in time. From the sample survey, which asks each household the number of days children were absent from school in the month before the survey date, we find that about 60 percent of the 95 eligible children who are not receiving the subsidy were absent on more than 15 percent of school days.

Table 3 presents some summary statistics of variables which are relevant to selection rules for households from FFE and non-FFE Unions as well as eligible versus non-eligible households within the FFE Unions. The first panel of Table 3 compares the total sample of households from FFE Unions with the total sample of households from non-FFE Unions. The data indicate that the FFE Unions are slightly less affluent than non-FFE Unions, with average annual household incomes for the two groups being Tk13,082 and Tk14,333, respectively. In addition, the FFE Unions have slightly smaller land holdings, and a higher percentage of household heads being a labourer, illiterate, and a higher percentage of female-headed households. None of these differences, however, are statistically significant. No detectable difference between average travel time to the nearest school is evident either.

Within the FFE Unions, however, the differences between non-eligible and eligible households are much larger. These differences are presented in the second panel of Table 3. Incomes of the non-eligible households are more than double that of the eligible households. The noneligible households have almost three times the land holdings of eligible households, and 11 per cent fewer household heads are labourers. These differences are statistically significant. The proportion of households headed by females is slightly higher for the eligible households than for non-eligible households, so is the proportion of household heads who are illiterate, though neither differences are statistically significant. These data seem to confirm that within each FFE union the degree of compliance with the FFE eligibility criteria is quite high.

Panel 3 of Table 3 compares the FFE-eligible households from the FFE Unions with all households from the non-FFE Unions. The differences in the relevant variables from this comparison are similar to those when comparing the FFE-eligible households with FFE-non-eligible households in the FFE Unions in panel 2, although the differences are larger for the latter than for the former. 
Given that the differences in the means of variables which are related to the selection rules are negligible between the FFE and non-FFE Unions, it would be interesting to compare the average difference in the two outcome variables, schooling participation and duration, for these two groups. These data are also presented at the bottom of Table 3. We find that for the primary-school-age children (6-13 years of age), neither the average school participation rate nor the average duration of schooling differs significantly between the FFE and non-FFE Unions. Should we conclude, therefore, that the FFE program has no effect on school participation and duration of schooling? It may be inappropriate to draw such a conclusion because some of the children from the FFE Unions are non-FFE participants. Table 3 also presents the mean difference in the two outcome variables for secondary-school-aged children (14-18 years of age), who are not subject to the FFE program in either FFE or non-FFE Unions. The data show that both the average school participation rate and the average duration of schooling for secondary students are significantly higher in the non-FFE Unions than their counterparts in the FFE Unions. It could be that without the FFE program the primary school participation rate for the FFE Unions would have been lower than the non-FFE Unions as well.

To further explore this issue, we compare the schooling outcome variables between the FFEeligible households and FFE non-eligible households in the FFE Unions in panel 2 of Table 3 and between the FFE-eligible households from the FFE Unions and households in the non-FFE Unions in panel 3 of the table. We find that on average primary-school-age children from the FFE-eligible households of the FFE Unions have a significantly higher school participation rate and stay at school longer than children of the same age from the other two groups. To the contrary, their older siblings on average are less likely to participate in school and stay at school for less time than children of the same age from the other two groups.

We plot these outcome variables for the three groups by age in Figure 1, which confirms that children between the ages of 6 and 13 from the FFE-eligible households in FFE Unions are the most likely group to attend school (top panel of Figure 1) and have, on average, more years of schooling (bottom panel of Figure 1) relative to both children from non-eligible households in FFE Unions and from households in the non-FFE Unions. The figure also shows that, for children above 13 years of age, the proportion who attend school and their average years of 
schooling, are both lower for children from FFE-eligible households than their counterfactuals in the other two groups.

The above simple mean comparisons suggest that the effect of the FFE program on school participation and duration of schooling for primary-school-age children is positive and statistically significant. These comparisons, however, do not take into account any differences in household and personal characteristics between different groups. Given that selection into the program is not random, these simple mean comparisons are biased. In the following sections more rigorous evaluations are conducted.

\section{Evaluation strategy}

As shown in Section 2, there are more eligible households than those receiving food subsidies due to the 40 per cent rule and other unobservaible individual and household characteristics which may deter a child from going to school, and hence, receiving the grain-subsidy. Previous studies of the FFE program evaluate the effect of the amount of grain-subsidy received on school attendance (Ravallion and Wodon, 2000; Ahmed, 2000; and Ahmed and del Ninno, 2002). Before discussing our evaluation strategy, we need to discuss why we decide to evaluate the effect of being eligible for the program (in the general evaluation literature, this is called "intention to treat" (ITT)) on school outcomes rather than the effect of receiving the grain subsidy on school outcomes. The FFE program has two special features, which are that (1) not every eligible child, but only those who are at school, can receive the grain subsidy, and (2) not every eligible child at school receives the grain-subsidy due to the maximum 40 rule. In this setting, if one is interested in evaluating whether the program increases school attendance, the effect of eligibility should be the most interesting evaluation to conduct. Below we list four reasons:

First, one of the rules for receiving a FFE grain subsidy is that the child has to go to school. Thus, if the treatment is measured as "receiving the grain-subsidy", by definition, every child who is in the treatment group is at school and there is a reverse causality between the treatment

and the outcome (being at school determines whether you can receive grain-subsidy or not). 
Second, the decision to attend school is made knowing that not attending school implies a zero probability of receiving the subsidy, whereas the probability of receiving a subsidy by attending school is very high, even though not a certainty in view of the 40 per cent limit. Thus, "eligibility to receive the grain-subsidy" induces children to go to school. Every child who goes to school in response to their eligibility should be counted as an effect of the program. The important impact of the program to be estimated, therefore, is the link between eligibility and schooling response. Third, from the perspective of policy makers, perhaps the most important policy instrument available to them is whether to make the household eligible or not, but not whether the children will take it up (enrolling in the primary schools which have the program) or not. Thus, the effect of "eligibility" is the most important parameter to estimate for policy makers (Rouse, 1998; Katz, King, and Liebman, 2001; and Bettinger and Slonim, 2005). Fourth, the estimation of the effect of "eligibility" requires less restrictions than the estimation of the effect of "receiving the grain-subsidy". Those who were eligible but did not receive the grain-subsidy may did so due to various reasons, such as family and individual unobservable characteristics which deter them from going to a school or due to unobservable characteristics of the school and teachers who do not allow an eligible child to obtain the grain-subsidy (similar argument can be seen, for example, in Bettinger and Slonim, 2005). Without the information on these unobservables, it is very hard to construct a control group which would satisfy the "Conditional Independence Assumption" required for the evaluation (see discussion below).

With regard to the outcome of schooling duration, the eligibility (Intention to Treat) should also be the most interesting evaluation to conduct. In addition to the points 3 and 4 listed above, which are applicable to any evaluation, we also know that one of the rules of the FFE program is that the subsidies given at school can be rotated among eligible children when those who are eligible exceed the 40 per cent limit per school (see discussion in Section 2). This rule implies that children who initially do not receive a food subsidy but remain in school, may eventually receive a subsidy providing the child is from an eligible household. Thus, staying on at school may be affected not only by whether the household is receiving a food-grain subsidy or not, but also by whether the child is eligible or not. This implies that there are more children who stay longer at school because of their eligibility status than those because they receive a 
grain-subsidy. As we evaluate the effect of eligibility on the two school outcomes, below we use treatment and eligibility interchangably.

Having defended our decision on evaluating the effect of eligibility, we are now in the position to set up the problem. Our purpose is to evaluate the effect of the FFE program eligibility on an outcome variable, $Y$. Assume this outcome variable depends on a set of exogenous variables, $X$, and on a treatment (eligibility), $d$. The evaluation problem can be expressed as:

$$
Y_{i}=X_{i} \beta+d_{i} \alpha+U_{i}
$$

where $\alpha$ measures the impact of the treatment for individual $i, \beta$ defines the relationship between $X$ and $Y$, while $U_{i}$ is the error term.

If assignment into the FFE program eligible group within the Unions which introduced the program is based on observable characteristics, we may assume that identification comes from selection on observables. If so, then the eligibility dummy variable $d$ should be uncorrelated with the error term $U$. In this case the simple regression estimation of equation (1) using a sample of households in the FFE Unions should provide a consistent estimate of the treatment effect, $\alpha$, providing that (1) $\alpha$ is homogenous across the eligible and non-eligible groups, and (2) $X$ includes all the variables affecting both eligibility and outcomes in the absence of FFE program. The assumption that conditional on $X, d$ and $U$ are uncorrelated is called the Conditional Independence Assumption. This assumption ensures that given $X$, the outcomes of non-eligible individuals are what the outcomes of eligible individuals would have been had they not been eligible (Rosenbaum and Rubin, 1985; Rubin, 1978; Blundell and Costa Dias, 2000; Ravallion, 2001).

However, two issues may prevent us from getting a consistent estimate of the effect of eligibility on our oucomes using OLS estimation. First, there may be non-compliance of the program assignment criteria, which may be associated with unobservable characteristics, which in turn is related to the outcome variable $Y$. If this is the case, then $d$ is related to $U$, and OLS estimation of equation (1) will be biased. The advantage of using "eligibility" rather than "receiving the grain-subsidy" in our study is that we effectively eliminated the problem of non- 
compliance. There is no reason to believe that non-compliance would occurr in the process of assigning households into eligible group.

Second, the OLS estimation of equation (1) assumes that in the control group, there are individuals who have exactly the same $X$ vectors as their eligible counterparts, which may or may not be the case. This is the so-called lack of common support condition (Black and Smith, 2002). Unless the treatment effect is homogenous, failure to satisfy the common support condition will course biased estimates of the treatment effect ( Heckman, Ichimura, Smith, and Todd, 1996 and Heckman, Ichimura, and Todd, 1997). It is very likely that the treatment effect, $\alpha$, is heterogenous between those who are eligible and those who are not within the FFE Unions. For example, giving a poor family $12 \mathrm{~kg}$ grain may induce them sending their children to school, but the same amount may have no effect on a rich family. Thus, assuming that given $X$, the outcomes of non-eligible individuals are what the outcomes of eligible individuals would have been had they not participated the program would be a too strong assumption.

Fortunately, our data include not only a sample of households who are from the FFE Unions, but also a sample of households who are from Non-FFE Unions. ${ }^{5}$ This richness of the data allows us to utilise the propensity score matching method to get around the problem of lack of common support and heterogenous treatment effect problem at household level (Rosenbaum and Rubin, 1985; Rubin, 1978; Blundell and Costa Dias, 2000; and Dehejia and Wahba, 2002). Like the linear regression estimate, propensity score matching assumes selection on observables. Unlike the linear regression estimate, in the case of our study, the assumption of selection on observables at household level is not defined over the sample of eligible and not eligible households within the FFE Unions, but between eligible households in the FFE Unions and potentially would-havebeen eligible control groups in non-FFE Unions. Even though on average the households from the non-FFE Unions are slightly more affluent than households from the FFE eligible households in the FFE Unions, some households within non-FFE Unions may in fact satisfy the selection criteria and would have been eligible for the program had they lived in the FFE Unions. Thus, these households serve as a valid counterfactual group. We, therefore, can confidently assume

\footnotetext{
${ }^{5}$ In addition, the survey not only include primary school children, but also secondary school children. The advantage of this data availability will be discussed below.
} 
that the treatment effect, $\alpha$, is homogeneous among our treatment and control groups, and that the selection of households into treatment (living in the FFE Unions) is exogenous (the decision of where to live is made long before the FFE program is introduced).

Nevertheless, selection at Union level is not random and poor and less literate Unions are more likely to be selected as discussed in Section 2. Thus, some unobservable regional effect could be correlated to both treatment, $d$, and the outcome variable, $Y$. This suggests that a simple matching method may not solve the potential endogeneity problem at the Union level, but matching combined with difference-in-differences will solve the problem. Below we provide a detailed discussion of our analytical strategy.

Propensity score matching assumes matching on $X$ is the same as matching on $P(X)$, where $P(X)=\operatorname{Pr}(d=1 \mid X)$. Thus, all the dimensions in $X$ can be summarised into a predicted probability of being eligible. We first estimate a probit model of whether a household is eligible for the program for the sample of household in the FFE Unions. Using these estimated results we then predict propensity scores of potential eligibility probability for households in the nonFFE Unions. Those in the non-FFE Unions who have the same or similar probability of being eligible for the program are then used as the counterfactuals for their eligible counterparts in the FFE Unions. To illustrate, assume $Y_{i}$ is the value of the outcome for individual $i$ from a eligible household, and $Y_{i}^{\prime}$ is the value of the outcome for the counterfactual, then the effect of the treatment on the treated, $\alpha$, can be defined as:

$$
\alpha_{i}=E\left(Y_{i}-Y_{i}^{\prime} \mid P(X), d=1\right)
$$

Note that as counterfactuals are from different regions, the simple matching method can not disentangle the influences of region, such as differences in the macro-economic environment and other unobservable factors. Thus, we may actually obtain:

$$
\alpha_{i}+R=E\left(Y_{i}-Y_{i}^{\prime} \mid P(X), d=1\right)
$$

where $R$ is the regional effect. However, utilising the richness in our data we are able to disentangle the effect of the treatment, $\alpha$, from the effect of the region, $R$. There might be two 
ways to control for the possible regional differences. First we can match children from non-FFE eligible households in the FFE Unions with their counterfactuals in non-FFE Unions (those who would not have been eligible for the program had the FFE program implemented in these Unions). As neither of these two groups participated in the program, the difference between them would be a pure regional difference. Thus, matching children from the eligible group in the FFE Unions with their counterparts from the non-FFE Unions and matching children from the non-eligible households in the FFE Unions with their counterparts from Non-FFE Unions give us equations (4) and (5) below, respectively:

$$
\begin{aligned}
& \left(Y_{i F F E_{1}}-Y_{i N F F E_{1}}^{\prime}\right)=\alpha_{i}+R, \\
& \left(Y_{i F F E_{0}}-Y_{i N F F E_{0}}^{\prime}\right)=R,
\end{aligned}
$$

where $Y_{i F F E_{1}}$ and $Y_{i F F E_{0}}$ refer to outcomes of the eligible and non-eligible groups in the FFE Unions, respectively, while $Y_{i N F F E_{1}}^{\prime}$ and $Y_{i N F F E_{0}}^{\prime}$ are outcomes of those who are from the nonFFE Unions but would-have-been eligible and would-not-have-been eligible (propensity scores are matched to the eligible and non-eligible groups in the FFE Union), respectively. The difference between equations (4) and (5) can distil the regional effect (both observables and unobservables), $R$, and leave us with a more accurate estimate of the treatment effect, $\alpha$. In the estimation section, this is referred to as "Diff-in-Diffs 1". Panel 1 of Figure 2 illustrates more clearly this matching combined with a difference-in-differences strategy. Note that for children from the Non-FFE Unions, we draw a dotted line to divide those who may be matched with the eligible (would-have-been eligible) and those who may be matched with non-eligible (would-not-have-been eligible) groups in the FFE Unions. This is because, based on propensity scores, there may be overlapping between the two groups, i.e. some children may be matched with both eligible and non-eligible children in the FFE Unions. In the estimation section, we test the sensitivity of such ambiguity empirically.

The second option to control for the regional effect is to use children who are beyond primary-school-age (i.e. 14 to 18 years, who are not eligible for the FFE program even if they 
are from FFE eligible households. The differences in schooling outcomes are evaluated between primary-school-age children who are from eligible households in FFE Unions and would-havebeen eligible households in non-FFE Unions and between beyond primary-school-age children who are from eligible households in FFE Unions and would-have-been eligible households in nonFFE Unions (see panel 2 of Figure 2 for a visual illustration of this matching strategy). The difference-in-differences between the two estimators can also be used to eliminate the effect of region on outcomes. This enables us to obtain another estimate of the treatment effect, $\alpha$. This difference-in-differences measure, referred to as "Diff-in-Diffs 2", however, implies the following assumptions. First, the regional effect on primary school attainment is the same as that on secondary school attainment. Second, there is no spill over effect of the program participation into secondary school children in the treated group. It is very unlikely that these assumptions can be satisfied. This will be discussed in detail later.

\section{Propensity score matching with difference-in-differences esti- mators}

To estimate propensity scores, a probit model of whether a child is from a program eligible household is estimated for a sample of children from FFE Unions. ${ }^{6}$ The dependent variable is whether the household is eligible for the program and the independent variables are age, age squared, and gender of the child, whether the child is a sister or brother of the household head as opposed to being his/her child or grandchild, ${ }^{7}$ mother and father's years of schooling, whether the household head is a labourer or not, the gender of the household head, and a group of household composition variables including number of male and female children in a household, number of primary-school-aged children in a household, and household size. In addition, we also include household total income, total land holding, total health expenditure, housing wealth, and other wealth. Further, to capture the community facility effect, we include distance between the home and the nearest primary school, the nearest bus stop, the nearest shop, and distance

\footnotetext{
${ }^{6}$ The results are available upon request from the authors.

${ }^{7}$ This may affect whether a child is sent to school or not as household head may treat their own children or grandchildren differently from their brothers or sisters.
} 
between home and the nearest drinking water. Finally, a group of dummy variables indicating the region (thana) of residency is also used. ${ }^{8}$ The estimated coefficients are then used to predict the probability of a child being in the program eligible group for children from both FFE and non-FFE Unions.

Figure 3 presents the distribution of predicted propensity scores (predicted probabilities) for the groups of children from the eligible and non-eligible households in the FFE and non-FFE Unions. The figure indicates that at the right tail of the distributions, where most individuals from the treatment group locate, there is a higher density of households from non-FFE Unions than from non-FFE households in FFE Unions. The mean predicted probability of being eligible for the treatment group is 0.66 , for non-FFE Unions it is 0.46 , while for non-FFE households in FFE Unions, it is 0.39 . These suggest that had the program been introduced in the nonFFE Unions, many households there would have been eligible to participate in the program, and hence, non-FFE Unions potentially provide a better common support condition for the treatment group. At the same time, we also observe that at the lower end of the propensity score distribution, there is a similar density of households from the non-FFE households in the FFE Unions and from non-FFE Unions. Thus, we may be able to divide households from the non-FFE Unions into pseudo treatment and control groups by matching their propensity scores with both the treatment group and children from non-FFE households in the FFE Unions so as to obtain a "Diff-in-Diffs 1" estimate.

The matching method used in this study is the "nearest neighbour matching" with replacement. This approach matches each treated unit with a single control unit which has the closest propensity score. Treated units for which no control unit is found within the maximum absolute distance specified are dropped. The distance is specified by setting a caliper width. As different caliper widths result in different numbers of treated units without a matching unit, the parameters being estimated will be different. To test robustness, we present results for two different caliper widths.

We match the eligible group with would-have-been eligible group and estimate the difference

\footnotetext{
${ }^{8}$ The reason we use Thana rather than Union is because when matching across FFE and non-FFE Unions, the Union dummy variables are orthogonal to program participation and, hence, makes the matching impossible.
} 
in their school participation rates. To eliminate the difference in the regional macro-economic environment and unobserviable factors between the two regions, we then match children from non-eligible households in the FFE Unions with children from would-not-have-been eligible households in the non-FFE Unions and obtain the difference in their school participation rates. Taking difference-in-differences of these two estimates provides a more accurate treatment effect on the treated (as shown in equations (4) and (5)).

There is, however, one issue which requires discussion. The way we define would-have-been and would-not-have-been eligible groups within the non-FFE Unions is by propensity score matching. It is possible, though, that some of the children in the non-FFE Unions can be matched both to the eligible and non-eligible groups in the FFE Unions. The overlapping of the matching will cause biased estimation of the treatment effect assuming a heterogenous treatment effect. To avoid this, we exclude those from would-have-been eligible group who are matched to the eligible group in the FFE Unions before matching the remainder to children from the non-eligible household in the FFE Unions.

These results are reported in the first panel of Table 4. They show that, relative to wouldhave-been eligible group, primary-school-aged children in the eligible group are 12 percentage points more likely to attend school. Comparing primary-school-age children from non-eligible households in the FFE Unions with their counterfactuals in non-FFE Unions, however, results in a large negative difference of 15 percentage points, indicating that primary-school-age children from the non-eligible group in the FFE Unions are much less likely to go to school than their counterfactuals in non-FFE Unions. The difference-in-differences measure indicates that the average effect of program eligibility on the primary school attendence is 27 percentage points. This difference is statistically significant at the 1 per cent level.

To test the sensitivity of this matching strategy, we also used the full sample of children from non-FFE Unions, including those who are matched with the eligible group, to match with children from non-eligible households in FFE Unions. The other exercise we did is to match children from non-FFE Unions with non-eligible households in FFE Unions first, and then exclude those who are matched from non-FFE Unions before matching the remainders to the FFE Union eligible group. These results are reported in Appendix A, which provides 
difference-in-differences measures of approximately the same order as those presented in Table 4, suggesting that our results are robust to alternative matching orders.

When we divided our sample into males and females, the matching results presented in panels 2 and 3 of Table 4 show that for males the difference in school participation rates between the eligible group in the FFE Unions and their counterfactuals in non-FFE Unions is small (4 to 6 percentage points) and not precisely estimated. For females, the school participation rate for the eligible group in FFE Unions is statistically significant and 17 percentage points higher than that of their counterfacturals from non-FFE Unions. The difference-in-differences estimation indicates a 15 to 18 percentage points improvement in school participation for boys and a 23 to 26 percentage point improvement for girls. Naturally, the main effect of the difference-indifferences estimation for the male sample is driven by the difference between the would-nothave-been eligible children from non-FFE Unions and those from non-eligible households in the FFE Unions, whereas for females, the result is driven mainly by the difference between the eligible group in FFE Unions and would-have-been eligible group from non-FFE Unions.

We also estimated "Diff-in-Diffs 2". The results are reported in Panel 4 of Table $4 .{ }^{9}$ They show that the treatment effects are 9 to 10 percentage points, although not statistically significant. To some extent, this may relate to the small matched sample size used for the older age group. For the total eligible group in FFE Unions and their counterfactuals in non-FFE Unions, there are only 53 and 32 children aged 14 to 18, respectively, when caliper is set equal to 0.01 , and 42 and 28 children, respectively when caliper is set to 0.05. In addition, as discussed earlier, using "Diff-in-Diffs 2" imposes two strong assumptions: a common regional effect for different age groups and no spill over effect of the FFE program for secondary-school-aged children.

The violation of the assumption of common regional effect may cause an overestimation of the program participation effect if the regional effect is larger for secondary school participation than for primary school participation. This seems plausible, as children of secondary-school-age may have more and better employment opportunities than their primary-school-aged counterparts and, hence, in poorer and less educated regions, demand for education may be lower, which, in

\footnotetext{
${ }^{9}$ Note that the estimated propensity score in this matching uses a sample of children aged 6 to 18 years. The propensity score distribution for this estimation is reported in Appendix B.
} 
turn, may generate the outcome of lack of secondary school provision in poorer regions.

The violation of the no spill over effect assumption may cause an under-estimation of the effect of the treatment if the spill over effect of the FFE program on secondary school participation is positive. Given that the program had been in operation for more than seven years when the survey was conducted, it is very likely that many children of secondary school age had been participants of the program when they were younger. The effect of spill over, however, is an empirical question, which may be tested. In our data information on the time the first child of the household entered the FFE program is available. Using this information we are able to exclude children who are aged 14 to 18 and who participated in the FFE program when they were in primary school. Excluding this sample of children (half of the children aged 14 to 18 from the eligible households in FFE Unions), we find that the difference-in-differences estimation is much larger than indicated in Table 4 (25 to 26 percentage points versus 9 to 10), suggesting that there is a spill over effect and the under-estimation caused by this effect is quite large (see the third panel of Appendix A). However, as the extent to which the assumption of a common regional effect may bias the results upward is not clear, we are unable to tell how close the effect estimated here is to the real effect of eligibility on school participation.

In addition to the school participation outcome, we also evaluate the effects of the FFE program on the duration of schooling, conditional on ever attending a school. As most of the children in the sample are still at school, the data on schooling duration is right-censored. The hazard model deals with this problem. To obtain an estimate of the completed duration of schooling we first estimate a piecewise constant hazard model of school duration ${ }^{10}$ and then use the estimated results to predict the completed schooling duration for each individual still at school, and hence, has a right censored dependent variable. ${ }^{11}$

To investigate the effect of FFE program eligibility on complete duration of schooling, the

\footnotetext{
${ }^{10}$ The piecewise constant hazard model is specified as: $\lambda\left(t_{i}\right)=e^{\beta \prime X_{i}} \lambda_{0}\left(t_{i}\right)$. Independent variables, $X$, included are the same as those included in the estimation of the propensity score model.

${ }^{11}$ The results from the estimated duration model are available upon request from the authors. Note that complete durations for the same individuals vary depending on the assumptions made by the researcher. When there are only primary school age children in the sample, the assumption is that nobody will continue schooling after primary school, whereas if there are children of secondary school aged in the sample, the assumption is that nobody will continue schooling beyond secondary school. The calculated complete schooling in the latter case should be much longer than for the former. In this paper we assume that nobody will continue schooling beyond secondary school rather than primary school.
} 
matching combined with difference-in-differences method is also employed and the results are reported in Table 5. The first panel of the table presents the results of "Diff-in-Diffs 1" using combined male and female samples. It shows that, on average, the eligible group has 0.53 to 0.54 of a year longer schooling than their would-have-been eligible counterparts in nonFFE Unions, while children of non-eligible households in FFE Unions have 0.15 to 0.17 of a year less schooling than children from the would-not-have-been group in non-FFE Unions. The difference-in-differences estimates indicate an average effect of eligibility of 0.7 year more schooling. The second and third panels of Table 5 report the same results for male and female samples, separately. For the male sample, we find a 0.8 to 0.9 of a year average effect of eligibility, whereas for the female sample the effect is slightly larger, ranging from 0.9 to 1.05 years.

The last panel of Table 5 presents results from the "Diff-in-Diffs 2" estimation, which indicates an average effect of eligibility of 1 to 1.1 years more schooling. Once again, we think that using the older group to eliminate the regional effect is less reliable for the same reasons mentioned earlier, though the results are similar to the "Diff-in-Diffs 1" estimation.

In summary, we find that the effect of the FFE eligibility on both school attendence and duration of schooling are quite large and this is especially true for girls. The result that the FFE eligibility has a larger effect on girls than boys is interesting. Our conjecture is that in a developing country where boy-preference is strong, poor households may prefer to send their sons to school rather than their daughters, and hence, had there been no FFE program, boys of the poor households would have been sent to school anyway. Thus, the FFE program actually provides incentives for parents to send their daughters to school. Schultz (2000) also found that the Mexican PROGRESA program had a larger effect on girls than boys.

The results obtained using PSM matching in this paper suggest a larger effect of eligibility on school participation than the effect found in Ahmed and del Ninno (2002) who evaluated the effect of the amount of grain-subsidy received on school participation. As the parameter of interest estimated between our study and theirs differs and the methodologies used also differ (they use IV estimate), it is not surprising that the findings are different. ${ }^{12}$

\footnotetext{
${ }^{12}$ Ravallion and Wodon (2000) using 1995-1996 Household Expenditure Survey data estimated the effect of
} 
Our findings of the effect of the FFE program on school enrollment and duration of schooling of children in Bangladesh are also higher than the findings of the effect of the Mexico PROGRESA program on the same outcomes (Schultz, 2000; Skoufias and McClafferty, 2001). They found a 7 and 14 percentage points increase in secondary school enrollment for boys and girls, respectively, and a 0.7 year increase in duration of schooling. The difference, however, is understandable due to the difference in country institutional settings, in the program settings, in treatment groups (primary school children vs. secondary school children), and the evaluation methodology used.

\section{Conclusions}

This paper has evaluated the effect of the Food for Education program implemented in Bangladesh. Although the FFE program has several objectives, our main focus has been its impact on primary school participation and school duration. We found that on average the FFE program increased the school attendance rate of the treated group by 15 to 26 percentage points, and increased their duration of schooling by 0.7 to 1.05 years.

The treatment effect of the FFE program is larger for girls than for boys, which is an important attribute of the FFE program, as girls are often not encouraged as much as boys are to attend school in developing countries.

the grain subsidy received on school participation. They find that every 114 Kilos of grain subsidy received increase children's school participation rate by 18 to 19 per cent. Given that their definition of treatment and methodology used differ from ours it is hard for us to compare their results with ours. 


\section{References}

[1] Ahmed, A.U., 2000, Targeted distribution. In Out of the Shadow of Famine: Evolving Food Markets and Food Policy in Bangladesh. Chepter 11, R. Ahmed, S. Haggblede, and TawfigE-Elani Choudhury (eds). Baltimore and London: The John Hopkins University Press for the International Food Policy Research Institute.

[2] Ahmed, A.U. and del Ninno, C., 2002. The food for education program in Bangladesh: An evaluation of its impact on educational attainment and food security. Food Consumption and Nutrition Division Discussion Paper No. 138. International Food Policy Research Institute, Washington D.C. (September).

[3] Alam, M., M.S. Hoque, C. Anwaruzzaman, O.H, Chowdhury and A.I. Sarkar. 1999. Enhancing accessibility to and retention in primary education for the rural poor in Bangladesh: An evaluation of the food for education program. Bangladesh Institute of Development Studies, Dhaka (June 7).

[4] Angrist, J. D. and Imbens, G. W., 1995, "Two-stage least squares estimation of average causal effects in models with variable treatment intensity", Journal of the American Statistical Association, 90(430), pp. 431-42.

[5] Angrist, J. D., Imbens, G. W., and Rubin, D. B., 1996, "Identification of causal effects using instrumental variables", Journal of the American Statistical Association, 91(434), pp. $444-55$.

[6] Black, D. and Smith, J., 2002, "How robust is the evidence on the effects of college quality? Evidence from matching", unpublished manuscript.

[7] Blundell, R. and Costa Dias, M., 2000, "Evaluation methods for non-experimental data", Fiscal Studies, 21(4), pp. 427-468.

[8] Dehejia, R. H., and Wahba, S., 2002, "Propensity score-matching methods for noneexperimental causal studies" Review of Economics and Statistics, 84(1), pp. 151-61.

[9] Bettinger, E., and Slonim, R., 2005, "Using experimental economics to measure the effects of a natural educational experiment on altruism", National Bureau of Economic Research NBER Working Papers:, 11725, 2005. 
[10] Heckman, J. J., Ichimura, H., and Todd, P. E., 1997, "Matching as an econometric evaluation estimator: evidence from evaluating a job training program", The Review of Economic Studies, 64, pp.605-654.

[11] Heckman, J. J., Ichimura, H., Smith, J., and Todd, P. E., 1996, "Sources of selection bias in evaluation social programs: an interpretation of conventional measures and evidence on the effectiveness of matching as a program evaluation method", Proceedings of the National Academy of Science, USA, 13416-13420.

[12] Imbens, G. W., 2003, "Sensitivity to exogeneity assumptions in program evaluation", American Economic Review, 93(2), pp.126-132.

[13] Katz, L., King, J., and Liebman, J., 2001, "Moving to opportunity in Boston: early results of a randomized mobility experiment", Quarterly Journal of Economics, 116(2), pp.607653.

[14] Ravallion, M., 2001, "The mystery of the vanishing benefits: an introduction to impact evaluation", The World Bank Economic Review, 15(1), pp.115-140.

[15] Ravallion, M. and Wodon, Q., 2001, "Does child labour displace schooling? Evidence on behavioural responses to an enrollment subsidy", Economic Journal, 110(March), pp. C158-C175.

[16] Rosenbaum, P. and Rubin, D. B., 1985, "Constructing a control group using multivariate matched sampling methods that incorporate the propensity score", American Statitician, 39, pp. 33-38.

[17] Rouse, C., 1998, "Private school vouchers and student achievement: an evaluation of the milwaukee parental choice program.", Quarterly Journal of Economics, 113(2), pp.553-602.

[18] Rubin, D. B., 1978, "Bayesian inference for causal effects: the role of randomization", Annals of Statistics, 7, pp. 34-58.

[19] Schultz, P., 2000, Final Report: The Impact of PROGRESA on School enrollments, International Food Policy Research Institute.

[20] Skoufias, E. and B. McClafferty. 2001. Is PROGRESA working? Summary of the results of an evaluation by IFPRI. Food Consumption and Nutrition Division Discussion Paper No. 118. International Food Policy Research Institute, Washington D.C. (July). 
[21] World Bank, 2001, Engendering Development, New York: Oxford University Press. 
Table 1: Distribution of household program participation between FFE and non-FFE Unions

\begin{tabular}{|c|c|c|c|c|}
\hline & \multicolumn{2}{|c|}{ FFE Union } & \multicolumn{2}{|c|}{ non-FFE Union } \\
\hline & No. of $\mathrm{HH}$ & $\begin{array}{l}\text { No. of children } \\
\text { aged } 6-13\end{array}$ & No. of $\mathrm{HH}$ & $\begin{array}{l}\text { No. of children } \\
\text { aged } 6-13\end{array}$ \\
\hline Participating households & 209 & 399 & & \\
\hline Non-Participating households & 191 & 336 & 200 & 343 \\
\hline
\end{tabular}

Source: Authors own calculation from IFPRI-FMRSP sample survey database as described in Ahmed and del Ninno (2002)

Table 2: Primary-school-aged children program participation status within FFE Unions

\begin{tabular}{llllll}
\hline \hline & \multicolumn{2}{l}{ FFE-Eligible Households } & & \multicolumn{2}{l}{ FFE-non-Eligible Households } \\
\cline { 2 - 3 } Including stipend program $^{\mathrm{a}}$ & Freq. & $\%$ & & Freq. & $\%$ \\
Total & 399 & 100 & & 336 & 100 \\
Not attending school & 55 & 13.78 & 102 & 30.36 \\
Attending Non-FFE school & 33 & 8.27 & 110 & 32.74 \\
Attending FFE school and receive & 216 & 54.14 & 0 & 0 \\
Attending FFE school not receive & 95 & 23.81 & 124 & 36.9 \\
Excluding stipend program participants & a & FFE-Eligible Households & & FFE-non-Eligible Households \\
Total & 388 & 100 & 319 & 31.97 \\
Not attending school & 55 & 14.18 & 102 & 29.15 \\
Attending Non-FFE school & 22 & 5.67 & 93 & 0 \\
Attending FFE school and receive & 216 & 55.67 & 0 & 38.87 \\
Attending FFE school not receive & 95 & 24.48 & 124 & 0 \\
\hline \hline
\end{tabular}

Source: Authors own calculation from IFPRI-FMRSP sample survey database as described in Ahmed and del Ninno (2002).

Note: a. The stipend program is separate to the FFE program. See footnote 4 in the paper. 
Table 3: Household $(\mathrm{HH})$ characteristics for FFE-eligible and non-eligible groups

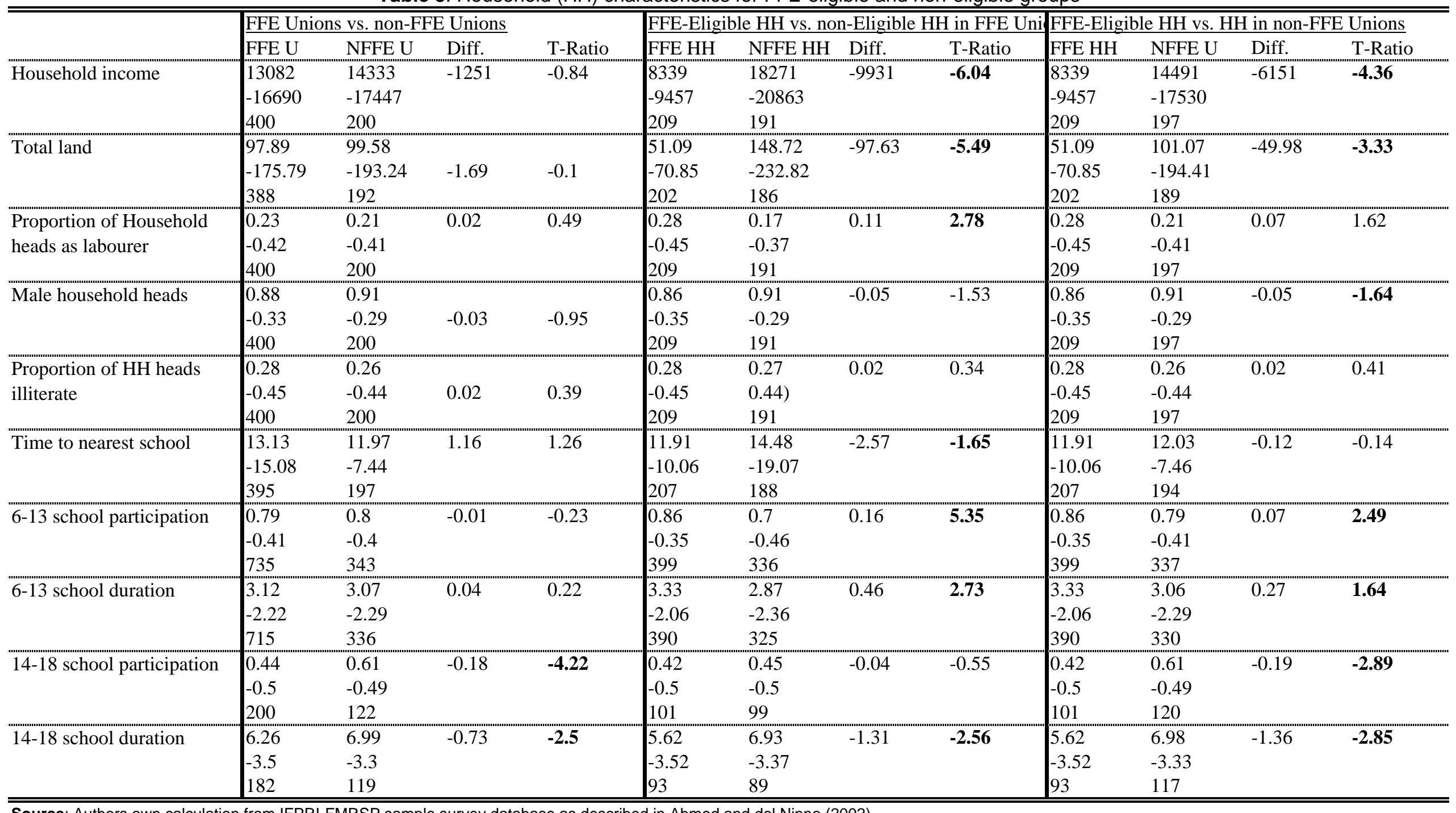

Source: Authors own calculation from IFPRI-FMRSP sample survey database as described in Ahmed and del Ninno (2002).

Note: Mean values are presented in the first row for each variable, standard deviations are in the second row in parentheses, and sample sizes are presented in the third row. 
Table 4: Propensity score matching combined with difference-in-differences on primary school particiaption rate

\begin{tabular}{|c|c|c|c|c|c|c|}
\hline \multirow{2}{*}{$\begin{array}{l}\text { Diff-in-Diffs } 1 \\
\text { Total sample }\end{array}$} & \multicolumn{2}{|c|}{ Treated vs. Control 1} & \multicolumn{2}{|c|}{$\begin{array}{l}\text { Unmatched in NFFE Unions } \\
\text { vs. NFFEHH in FFE Unions }\end{array}$} & \multicolumn{2}{|c|}{ Difference-in-Differences } \\
\hline & caliper $=0.01$ & caliper $=0.005$ & caliper $=0.01$ & caliper $=0.005$ & caliper $=0.01$ & caliper $=0.005$ \\
\hline Effect & 0.12 & 0.12 & -0.15 & -0.15 & 0.27 & 0.27 \\
\hline Std err & 0.05 & 0.05 & 0.06 & 0.06 & & \\
\hline T-ratios & 2.61 & 2.61 & 2.40 & 2.43 & 3.48 & 3.51 \\
\hline matched treated & 355 & 338 & 267 & 197 & & \\
\hline matched controls & 155 & 155 & 93 & 87 & & \\
\hline total treated & 389 & 389 & 319 & 319 & & \\
\hline total controls & 306 & 306 & 151 & 152 & & \\
\hline$\%$ of treated matched & 91.26 & 86.89 & 83.70 & 61.76 & & \\
\hline \multicolumn{6}{|l|}{ Male sample } & \\
\hline Effect & 0.06 & 0.04 & -0.12 & -0.11 & 0.18 & 0.15 \\
\hline Std err & 0.06 & 0.06 & 0.08 & 0.09 & & \\
\hline T-ratios & 0.96 & 0.65 & 1.47 & 1.26 & 1.76 & 1.41 \\
\hline matched treated & 159 & 126 & 123 & 83 & & \\
\hline matched controls & 80 & 76 & 54 & 50 & & \\
\hline total treated & 188 & 188 & 159 & 159 & & \\
\hline total controls & 165 & 165 & 89 & 89 & & \\
\hline$\%$ of treated matched & 84.57 & 67.02 & 77.36 & 52.20 & & \\
\hline$\%$ of controls matched & 48.48 & 46.06 & 60.67 & 56.18 & & \\
\hline \multicolumn{7}{|l|}{ Female sample } \\
\hline Effect & 0.17 & 0.17 & -0.06 & -0.09 & 0.23 & 0.26 \\
\hline Std err & 0.07 & 0.07 & 0.10 & 0.10 & & \\
\hline T-ratios & 2.48 & 2.40 & 0.62 & 0.88 & 1.98 & 2.10 \\
\hline matched treated & 183 & 135 & 84 & 68 & & \\
\hline matched controls & 73 & 68 & 43 & 41 & & \\
\hline total treated & 208 & 208 & 160 & 160 & & \\
\hline total controls & 141 & 141 & 73 & 73 & & \\
\hline$\%$ of treated matched & 87.98 & 64.90 & 52.50 & 42.50 & & \\
\hline$\%$ of controls matched & 51.77 & 48.23 & 58.90 & 56.16 & & \\
\hline Diff-in-Diffs 2 & \multicolumn{2}{|c|}{$\begin{array}{c}\text { Treated vs. Control } 1 \text { for } \\
\text { aged 6-13 }\end{array}$} & \multicolumn{2}{|c|}{$\begin{array}{c}\text { Treated vs. Control } 1 \text { for } \\
\text { aged } 14-18\end{array}$} & \multicolumn{2}{|c|}{ Difference-in-Differences } \\
\hline Total sample & caliper $=0.01$ & caliper $=0.005$ & caliper $=0.01$ & caliper $=0.005$ & caliper $=0.01$ & caliper $=0.005$ \\
\hline Effect & 0.10 & 0.09 & 0.00 & 0.00 & 0.10 & 0.09 \\
\hline Std err & 0.05 & 0.05 & 0.12 & 0.12 & & \\
\hline T-ratios & 2.32 & 1.86 & 0.00 & 0.00 & 0.82 & 0.66 \\
\hline matched treated & 297 & 254 & 53 & 42 & & \\
\hline matched controls & 137 & 129 & 32 & 28 & & \\
\hline total treated & 388 & 388 & 88 & 88 & & \\
\hline total controls & 306 & 306 & 93 & 93 & & \\
\hline$\%$ of treated matched & 76.55 & 65.46 & 60.23 & 47.73 & & \\
\hline$\%$ of controls matched & 44.77 & 42.16 & 34.41 & 30.11 & & \\
\hline
\end{tabular}

Note: clp refers to caliper width used to match observations. 
Table 5: Propensity score matching combined with difference-in-differences on complete duration of schooling

\begin{tabular}{|c|c|c|c|c|c|c|}
\hline \multirow{2}{*}{$\begin{array}{l}\text { Diff-in-Diffs } 1 \\
\text { Total sample }\end{array}$} & \multicolumn{2}{|c|}{ Treated vs. control 1} & \multicolumn{2}{|c|}{$\begin{array}{l}\text { Unmatched in NFFE Unions } \\
\text { vs. NFFEHH in FFE Unions }\end{array}$} & \multicolumn{2}{|c|}{ Difference-in-Differences } \\
\hline & $\mathrm{clp}=0.01$ & $\mathrm{clp}=0.005$ & $\mathrm{clp}=0.01$ & $\mathrm{clp}=0.005$ & $\mathrm{clp}=0.01$ & $\mathrm{clp}=0.005$ \\
\hline Effect & 0.53 & 0.54 & -0.17 & -0.15 & 0.70 & 0.70 \\
\hline Std. Err. & 0.08 & 0.08 & 0.13 & 0.13 & & \\
\hline t-ratio & 6.74 & 6.67 & 1.30 & 1.15 & 4.66 & 4.50 \\
\hline matched treated & 291 & 251 & 174 & 156 & & \\
\hline matched controls & 144 & 137 & 95 & 93 & & \\
\hline total treated & 388 & 388 & 319 & 319 & & \\
\hline total controls & 307 & 307 & 162 & 169 & & \\
\hline$\%$ of treated matched & 75.00 & 64.69 & 54.55 & 48.90 & & \\
\hline$\%$ of controls matched & 46.91 & 44.63 & 58.64 & 55.03 & & \\
\hline \multicolumn{7}{|l|}{ Male sample } \\
\hline use old group & $c l p=0.01$ & $\mathrm{clp}=0.005$ & $\mathrm{clp}=0.01$ & $\mathrm{clp}=0.005$ & $\mathrm{clp}=0.01$ & $\mathrm{clp}=0.005$ \\
\hline Effect & 0.43 & 0.38 & -0.36 & -0.50 & 0.79 & 0.89 \\
\hline Std. Err. & 0.15 & 0.17 & 0.20 & 0.22 & & \\
\hline t-ratio & 2.87 & 2.28 & 1.80 & 2.33 & 3.17 & 3.24 \\
\hline matched treated & 85 & 67 & 74 & 68 & & \\
\hline matched controls & 57 & 50 & 55 & 53 & & \\
\hline total treated & 181 & 181 & 159 & 159 & & \\
\hline total controls & 165 & 165 & 108 & 108 & & \\
\hline$\%$ of treated matched & 46.96 & 37.02 & 46.54 & 42.77 & & \\
\hline$\%$ of controls matched & 34.55 & 30.30 & 50.93 & 49.07 & & \\
\hline \multicolumn{7}{|l|}{ Female sample } \\
\hline use old group & $\mathrm{clp}=0.01$ & $\mathrm{clp}=0.005$ & $c l p=0.01$ & $\mathrm{clp}=0.005$ & $\mathrm{clp}=0.01$ & $\mathrm{clp}=0.005$ \\
\hline Effect & 0.90 & 0.95 & 0.00 & -0.10 & 0.90 & 1.05 \\
\hline Std. Err. & 0.22 & 0.24 & 0.35 & 0.42 & & \\
\hline t-ratio & 4.08 & 4.00 & 0.00 & 0.23 & 2.16 & 2.16 \\
\hline matched treated & 121 & 99 & 55 & 44 & & \\
\hline matched controls & 70 & 62 & 37 & 30 & & \\
\hline total treated & 207 & 207 & 160 & 160 & & \\
\hline total controls & 142 & 142 & 71 & 79 & & \\
\hline$\%$ of treated matched & 58.45 & 47.83 & 34.38 & 27.50 & & \\
\hline$\%$ of controls matched & 49.30 & 43.66 & 52.11 & 37.97 & & \\
\hline Diff-in-Diffs 2 & \multicolumn{2}{|c|}{$\begin{array}{l}\text { Treated vs. Control } 1 \text { for aged } \\
6-13\end{array}$} & \multicolumn{2}{|c|}{$\begin{array}{l}\text { Treated vs. Control } 1 \text { for aged } \\
\qquad 14-18\end{array}$} & \multicolumn{2}{|c|}{ Difference-in-Differences } \\
\hline Total sample & $c l p=0.01$ & $\mathrm{clp}=0.005$ & $c l p=0.01$ & $\mathrm{clp}=0.005$ & $\mathrm{clp}=0.01$ & $\mathrm{clp}=0.005$ \\
\hline Effect & 0.53 & 0.54 & -0.54 & -0.44 & 1.07 & 0.98 \\
\hline Std. Err. & 0.08 & 0.08 & 0.48 & 0.52 & & \\
\hline t-ratio & 6.74 & 6.67 & 1.12 & 0.84 & 2.21 & 1.86 \\
\hline matched treated & 291 & 251 & 43 & 36 & & \\
\hline matched controls & 144 & 137 & 26 & 23 & & \\
\hline total treated & 388 & 388 & 88 & 88 & & \\
\hline total controls & 307 & 307 & 93 & 93 & & \\
\hline$\%$ of treated matched & 75.00 & 64.69 & 48.86 & 40.91 & & \\
\hline$\%$ of controls matched & 46.91 & 44.63 & 27.96 & 24.73 & & \\
\hline
\end{tabular}

Notes: (1) clp refers to caliper width used to match observations.

(2) Complete durations are predicted durations from the schooling duration hazard model estimated for children aged 6 to 18. The results of the estimated hazard model are available upon request from the authors.

(3) Std. Errs and t-ratios reported may be biased because complete durations are predicted from a hazard model. 
Figure 1: Primary school participation and years of schooling by age and participation status

\section{Proportion of primary school participants}

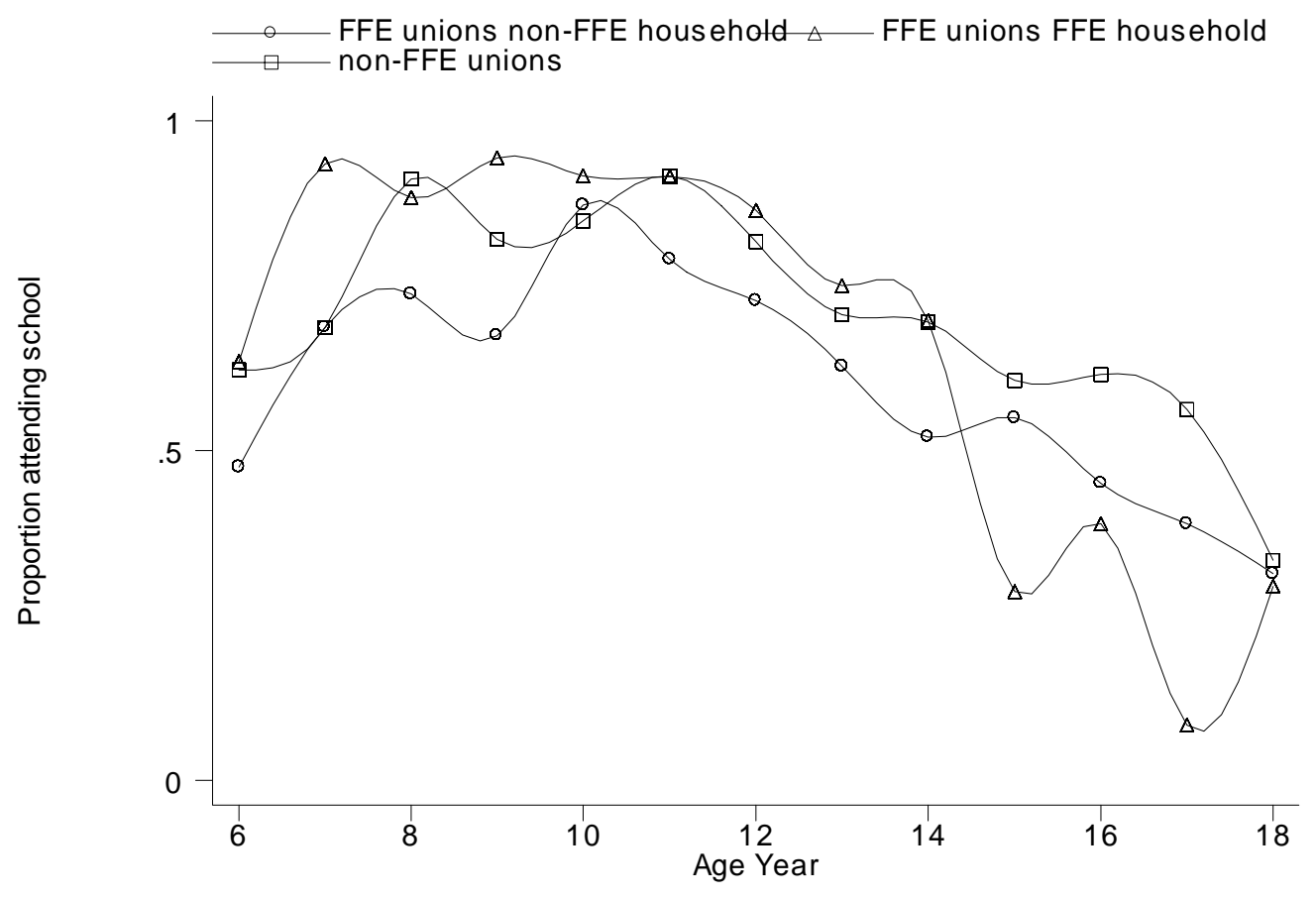

Average years of schooling

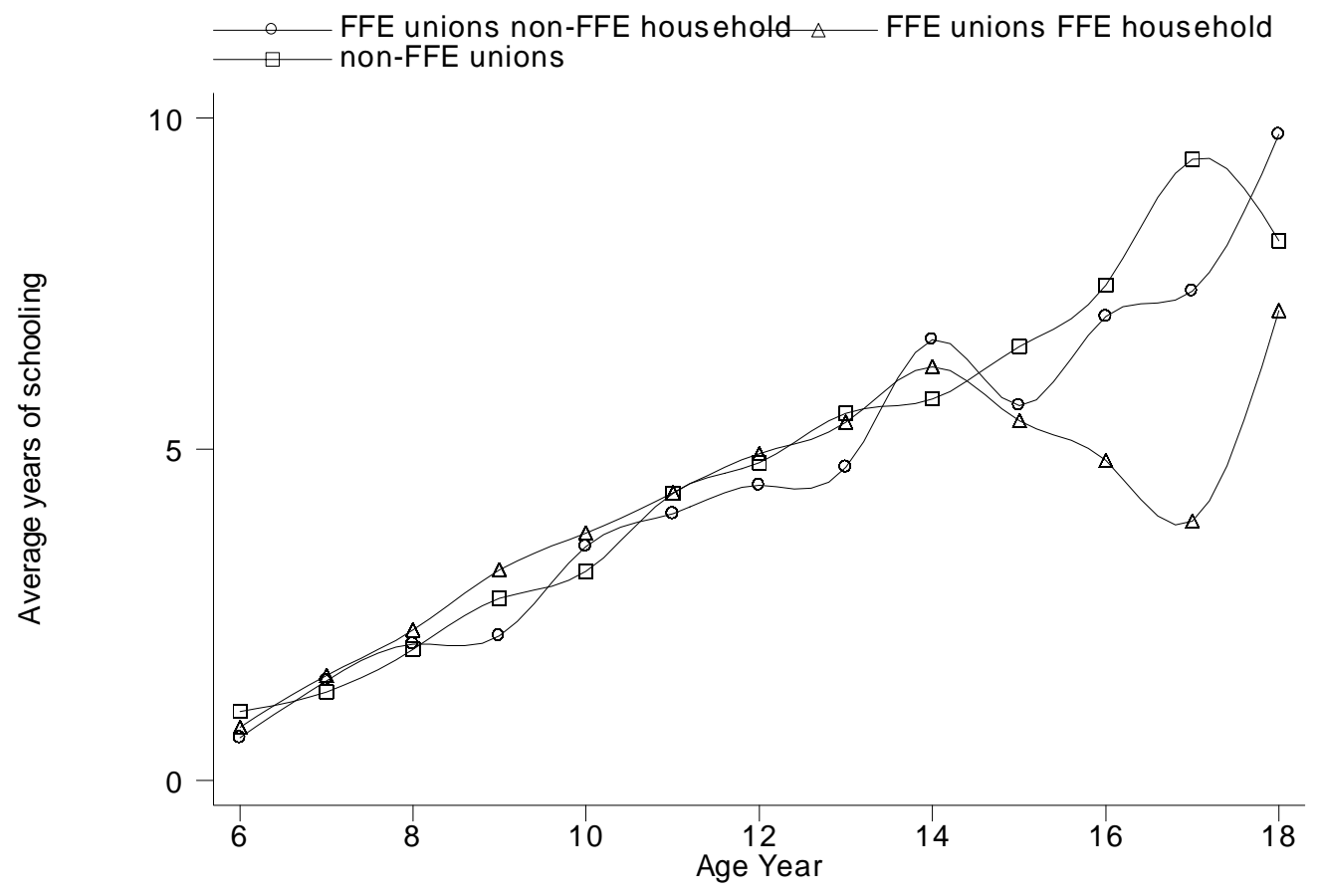


Figure 2: Illustration of the methodology of using PS matching combined with difference-in-differences

UNIONS

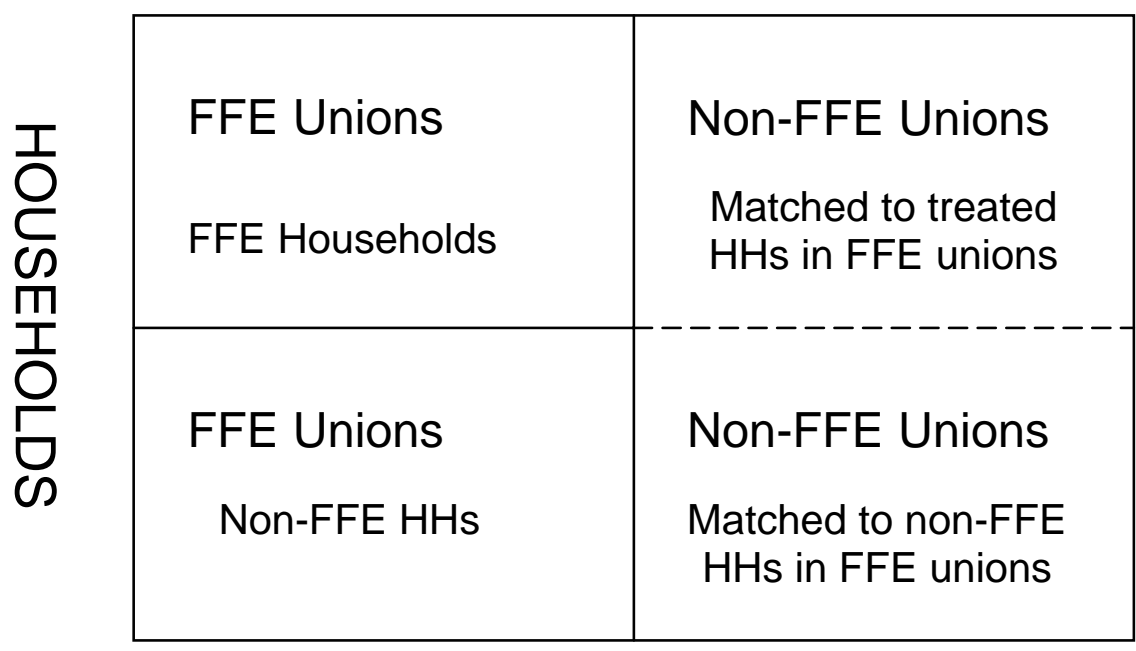

\section{UNIONS}

\begin{tabular}{|c|c|}
\hline $\begin{array}{l}\text { FFE Unions treated } \\
\text { households } \\
\qquad \text { Aged } 6 \text { to } 13\end{array}$ & $\begin{array}{l}\text { Non-FFE Unions } \\
\text { Matched to treated } \\
\text { Aged } 6 \text { to } 13\end{array}$ \\
\hline $\begin{array}{l}\text { FFE Unions treated } \\
\text { households } \\
\text { Aged } 14-18\end{array}$ & $\begin{array}{l}\text { Non-FFE Unions } \\
\text { Matched to treated } \\
\text { Aged } 14 \text { to } 18\end{array}$ \\
\hline
\end{tabular}


Figure 3: Distribution of propensity score for the three groups using sample of children aged 6 to 13 years

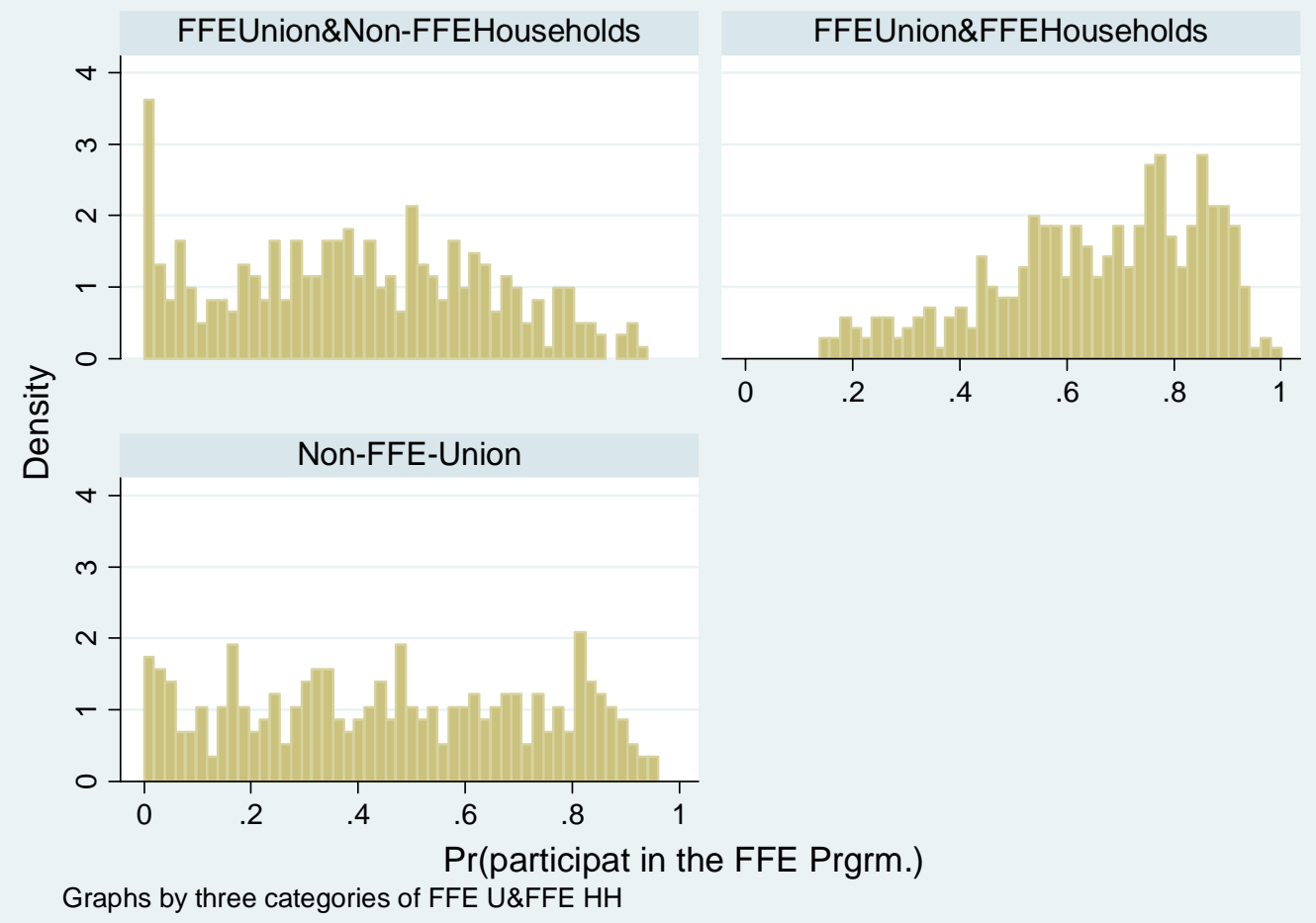




\section{Appendix A: Sensitivity tests for Table 4}

\begin{tabular}{|c|c|c|c|c|c|c|}
\hline \multirow[b]{2}{*}{ Total } & \multicolumn{2}{|c|}{ Treated vs. Control 1} & \multicolumn{2}{|c|}{$\begin{array}{l}\text { Unmatched in NFFE Unions } \\
\text { vs. NFFEHH in FFE Unions }\end{array}$} & \multicolumn{2}{|c|}{ Difference-in-Differences } \\
\hline & caliper=0.01 & caliper=0.005 & caliper $=0.01$ & caliper $=0.005$ & caliper=0.01 & caliper $=0.005$ \\
\hline Effect & 0.11 & 0.16 & -0.14 & -0.13 & 0.25 & 0.29 \\
\hline Std err & 0.07 & 0.07 & 0.05 & 0.04 & & \\
\hline T-ratios & 1.42 & 2.27 & 3.08 & 3.02 & 2.81 & 3.51 \\
\hline matched treated & 313 & 234 & 308 & 295 & & \\
\hline matched controls & 79 & 76 & 170 & 169 & & \\
\hline total treated & 389 & 389 & 319 & 319 & & \\
\hline total controls & 136 & 136 & 307 & 307 & & \\
\hline$\%$ of treated matched & 80.46 & 60.15 & 96.55 & 92.48 & & \\
\hline$\%$ of controls matched & 58.09 & 55.88 & 55.37 & 55.05 & & \\
\hline $\begin{array}{l}\text { Using total sample from } \\
\text { NFFE unions }\end{array}$ & \multicolumn{2}{|c|}{ Treated vs. Control 1} & \multicolumn{2}{|c|}{$\begin{array}{l}\text { All kids from NFFE unions vs. } \\
\text { NFFEHH in FFE Unions }\end{array}$} & \multicolumn{2}{|c|}{ Difference-in-Differences } \\
\hline Total & caliper $=0.01$ & caliper $=0.005$ & caliper=0.01 & caliper $=0.005$ & caliper=0.01 & caliper $=0.005$ \\
\hline Effect & 0.12 & 0.12 & -0.12 & -0.12 & 0.24 & 0.25 \\
\hline Std err & 0.05 & 0.05 & 0.05 & 0.05 & & \\
\hline T-ratios & 2.61 & 2.61 & 2.57 & 2.57 & 3.64 & 3.66 \\
\hline matched treated & 355 & 338 & 310 & 297 & & \\
\hline matched controls & 155 & 155 & 163 & 159 & & \\
\hline total treated & 389 & 389 & 319 & 319 & & \\
\hline total controls & 306 & 306 & 307 & 307 & & \\
\hline$\%$ of treated matched & 91.26 & 86.89 & 97.18 & 93.10 & & \\
\hline$\%$ of controls matched & 50.65 & 50.65 & 53.09 & 51.79 & & \\
\hline $\begin{array}{l}\text { Excluding older children } \\
\text { who used to be treated }\end{array}$ & \multicolumn{2}{|c|}{$\begin{array}{l}\text { Treated vs. Control } 1 \text { for aged } \\
6-13\end{array}$} & \multicolumn{2}{|c|}{$\begin{array}{l}\text { Treated vs. Control } 1 \text { for aged } \\
\text { 14-18 }\end{array}$} & \multicolumn{2}{|c|}{ Difference-in-Differences } \\
\hline Total & caliper=0.01 & caliper $=0.005$ & caliper=0.01 & caliper $=0.005$ & caliper=0.01 & caliper $=0.005$ \\
\hline Effect & 0.09 & 0.08 & -0.16 & -0.18 & 0.25 & 0.26 \\
\hline Std err & 0.04 & 0.05 & 0.13 & 0.14 & & \\
\hline T-ratios & 2.00 & 1.70 & 1.20 & 1.29 & 1.77 & 1.76 \\
\hline matched treated & 302 & 247 & 25 & 22 & & \\
\hline matched controls & 139 & 128 & 19 & 17 & & \\
\hline total treated & 388 & 388 & 44 & 44 & & \\
\hline total controls & 306 & 306 & 93 & 93 & & \\
\hline$\%$ of treated matched & 77.84 & 63.66 & 56.82 & 50.00 & & \\
\hline$\%$ of controls matched & 45.42 & 41.83 & 20.43 & 18.28 & & \\
\hline
\end{tabular}

Note: clp refers to caliper width used to match observations. 


\section{Appendix B:}

Propensity scores for the three groups using sample of children aged 6 to 18 years

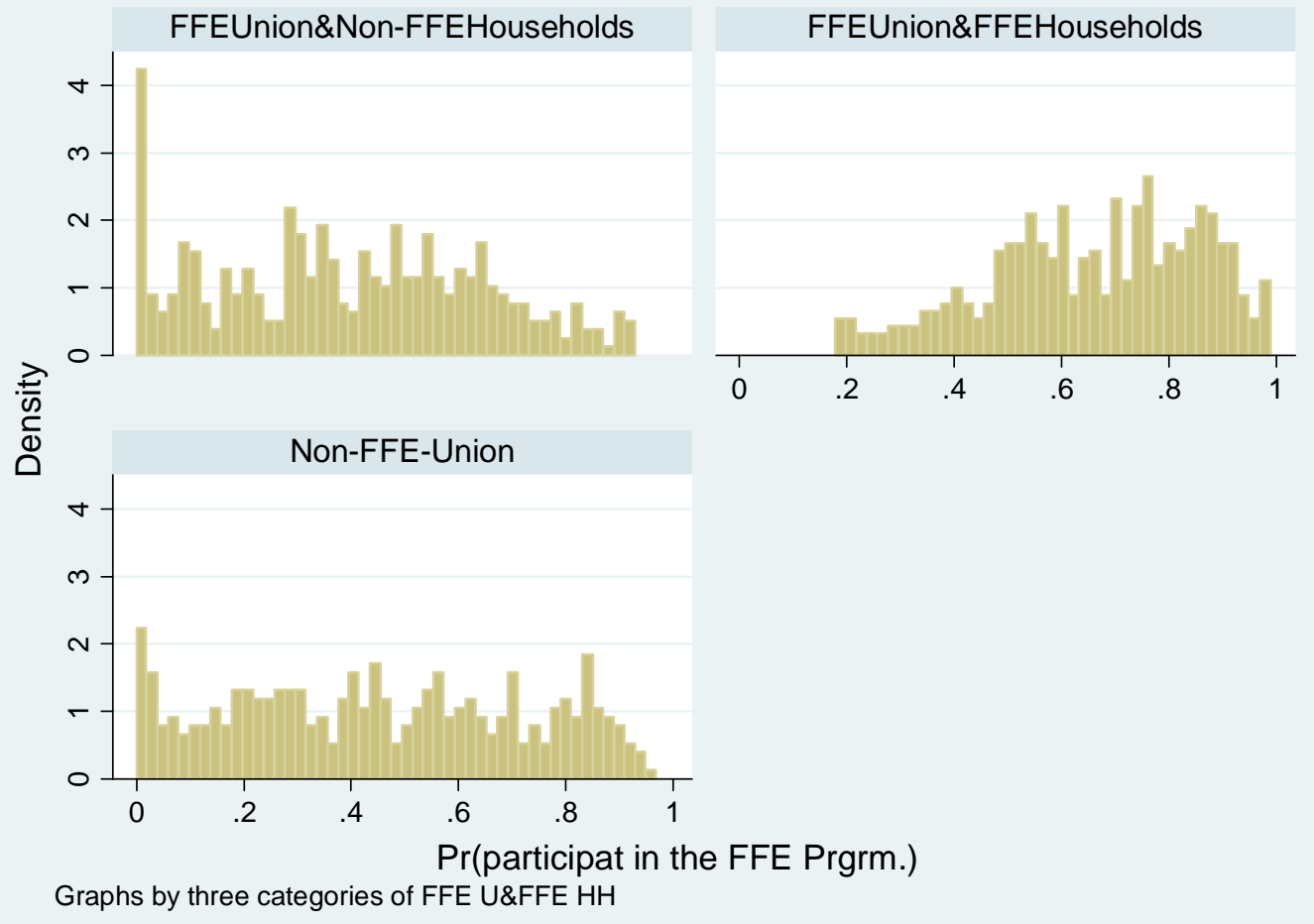

